\title{
Synergy of Savonius and Darrieus types for vertical axis wind turbine
}

\author{
A.M.M. Almotairi ${ }^{1}$, F. Mustapha ${ }^{1, *}$, M.K.A. Mohd Ariffin ${ }^{2}$, R. Zahari ${ }^{1}$ \\ ${ }^{1}$ Department of Aerospace Engineering, Universiti Putra Malaysia 43400 Serdang, Selangor, Malaysia \\ ${ }^{2}$ Department of Mechanical and Manufacturing Engineering, Universiti Putra Malaysia 43400 Serdang, Selangor, Malaysia
}

\section{A R T I C LE IN F O}

\section{Article history:}

Received 10 August 2016

Received in revised form

2 October 2016

Accepted 10 October 2016

\section{Keywords:}

Darrieus

Renewable energy

Savonius

Vertical axis wind turbine

Wind energy

\begin{abstract}
A B S T R A C T
Wind energy is one of the renewable energy sources or technology which is the cheapest the and cleanest compared to other types of energy. A new market in wind technology has emerged that has the means of efficiently convert the wind energy to a usable form of energy which is electricity. The foundation of this new technology is the wind turbine. Wind turbine is a machine that transfers fluid energy that passed through the blades and shaft to mechanical energy and transforms the mechanical energy to electricity through the use of a generator. Vertical Axis Wind Turbine (VAWT) has been popular due to its small, quiet and simple design. Darrieus, Savonius, and Vane are the example of VAWT. This vertical axis wind turbine represents a suitable alternative for wind power extraction in many developing countries. The reason for this is mainly because of the advantage over the horizontal axis type such as Simple construction, extremely cost effective and acceptance of wind flow from any direction without orientation. In spite of these advantages, vertical axis wind turbine is not gaining popularity because of low efficiency of the Savonius type rotor and low starting torque of the Darrieus type wind machines. Hence, the objective of this paper is to design a VAWT by combining the Savonius type and Darrieus type so that the combination of these both designs is met the expectation to have a good performance of wind turbine.
\end{abstract}

(C) 2016 The Authors. Published by IASE. This is an open access article under the CC BY-NC-ND license (http://creativecommons.org/licenses/by-nc-nd/4.0/).

\section{Introduction}

The Horizontal Axis Wind Turbine (HAWT) is the most common and can frequently be seen littered across the landscape in areas of comparatively level ground with predictable year round wind conditions. HAWT sit atop a great column and hold a lot of blade that revolve about an axis parallel to the current direction. These wind turbines have been the primary issue of wind turbine research for decades, primarily because they share common operation and dynamics with rotary aircraft. In HAWT, there are two primary types; one is the wind turbine that face into the wind and the other one is that face away from the wind. Turbines that face into the wind require a rudder or some other type of mechanism to be able to self-orientate to face the incoming current of air. Those that face away from the wind do not

\footnotetext{
* Corresponding Author.

Email Address: faizalms@upm.edu.my (F. Mustapha)

https://doi.org/10.21833/ijaas.2016.10.005

2313-626X/@ 2016 The Authors. Published by IASE.

This is an open access article under the CC BY-NC-ND license

(http://creativecommons.org/licenses/by-nc-nd/4.0/)
}

need this reader to self-orientate; however, they suffer from a vibration due to the support tower blocking part of the wind flow (Carrigan et al., 2012).

While the Vertical Axis Wind Turbine (VAWT) rotate about an axis that is perpendicular to the oncoming flow, hence, it can take wind from any directions which lead them to be more versatile. VAWT are rugged, quiet, omni-directional, and they do not create as much stress on the support structure. They can be packed closer together in wind farms, allowing more in a given space. This is not because they are smaller, but rather due to the slowing effect that HAWT have on the air, forcing designers to separate them by ten times their width. The VAWT is not as efficient as the HAWT and it has very low starting torque, as well as dynamic stability problems, but it offers benefits in low wind situations where the traditional HAWT has difficulties operating. The main benefits obtained are improved performance at lower wind speeds and lower revolutions per minutes. Regime at higher wind speeds resulting in a silent turbine suitable for residential environments. It also tends to be safer and easier to build, and it can be assembled close to 
the ground and handle turbulence much better than the horizontal one.

VAWTs consist of two major characters, the Darrieus rotor and Savonius rotor. The Darrieus wind turbine is a VAWT that rotates about a central axis due to the lift produced by the rotating surfaces, whereas a Savonius rotor rotates due to the drag created by its blades. There is likewise a raw type of VAWT emerging in the wind power industry, which is a mix between the Darrieus and Savonius designs. All the wind turbine types mentioned can be found out in Fig. 1.

After the World War 1, G.J.M. Darrieus, a French aeronautical engineer, invented a VAWT by adopting air foil profile for the blades. The designed was patented in France in 1925 and in the US in 1931 and put the working principle as a bio-mimicry of birds' wings by stating, "It is thus possible to give these blades a stream line section analogous to that of the wings of birds, that is to say, offering the minimum resistance to forward movement and capable of converting into mechanical energy the maximum available amount of energy of the fluid by means of the useful component of the traverse thrust which this section undergoes". The patent covered two main configurations: curved and straight blades (Tjiu et al., 2015). This turbine has been the starting point for further studies on VAWT, to improve efficiency. The Darrieus wind turbines consist of a bit of curved airfoil blades mounted on the vertical rotating shaft or framework.

In 1992, Sigurd J. Savanious the engineer of Finnish, he has invented the Savanious wind turbines. Even so, the first person that tries to make a horizontal wind generator of the Savanious type in the town of Furstenburg in Germany was Johann Ernst Elias Bessler in 1745. Today they are not normally related to electric power grids (Marco and Medaglia, 2010). The Savanious are one of the simplest self-starting vertical-axis turbines. Aerodynamically, these turbines are drag-type VAWT, so it cannot rotate faster than the wind speed. This means that the tip speed ratio is smaller, making this type of turbines are not suitable for electricity generation.

\section{Renewable energy}

Green energy or renewable energy has become important nowadays. The application of renewable energy helps people overcome the problem of the continuous decreasing of fuel resources. Natural resources such as wind, sunlight, rain and geothermal heat are utilised efficiently in energy services such as power generation, heating and transport fuel. The development and research drive for renewable energy has become crucial and continues to rise rapidly, ever since the emergence of the world energy crisis in the 1970s.

Globally, wind energy has a big potential in terms of renewable energy. It can supply more than double the current world electricity consumption, which is about $15,000 \times 10^{9} \mathrm{kWh}$ per year. The supply can achieve from $20,000 \times 10^{9}-50,000 \times 10^{9} \mathrm{kWh}$ per year (Herbert et al., 2007; Hashim and Ho, 2011). This depends on several factors such as the average wind speed, the statistical wind speed distribution, turbulence intensities and the cost of wind turbine systems. Besides this, there are more than 50 countries and 1500 organisations contributing hardware manufacturing, project development, power generation, finance and consultancy. This huge number expedites the enhancements and advancements of wind energy technology.

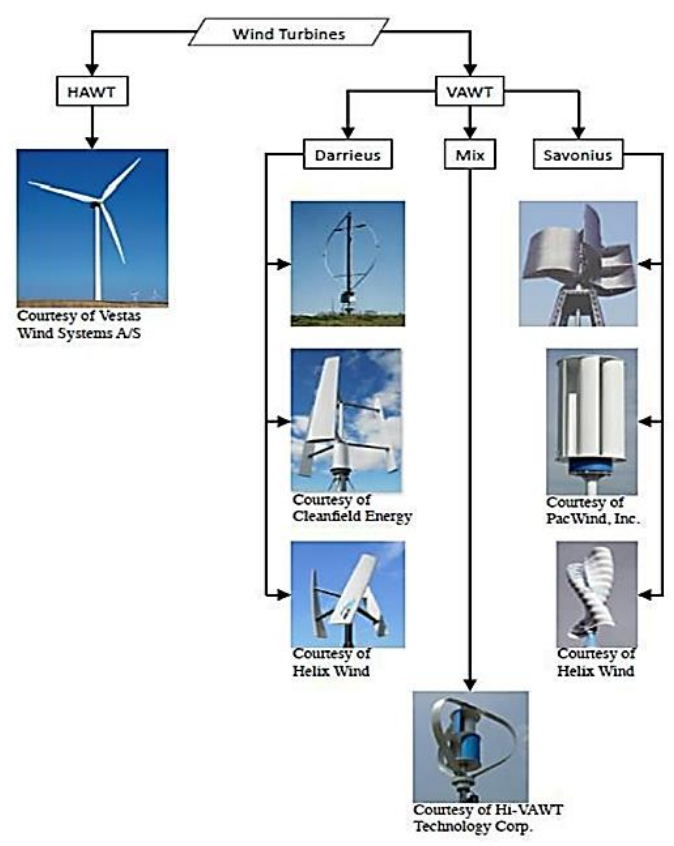

Fig. 1: Types of wind turbines

Fig. 2 shows data for the comparison of cumulative wind power installed in several countries at 2004, 2010, 2011 and 2012 (Leung and Yang, 2012, Herbert et al., 2007). It shows that China has become the new champion of wind power generation around the world with a cumulative power of 75,324 MW. This is followed by the United States with 60,007 MW, Germany with 31,308 MW, Spain with 22,796 MW and India with 18,421 MW. The new installation trend in global industry for 2004 and 2012 is reported in Fig. 3. Europe dominates the trend with $4825 \mathrm{MW}$ in2004 but Asia defeated the trend with 15,510 MW of new installations of wind power. This indicates that Asia is a potential region for enhancing the technology, as this may be due to demand and the appropriate geographic factor. Additionally, the reports above obviously show that the technology of wind energy is evolving tremendously and contributes to the development of the renewable energy sector.

\section{Vertical axis wind turbine (VAWT)}

Wind turbines can be categorised into two main types, depending on the axial direction of the rotor shaft. One type is the Horizontal Axis Wind Turbine (HAWT) and the second type is the Vertical Axis Wind Turbine (VAWT). HAWTs have blades 
mounted radially from the rotor. Modern types usually have two or three blades and are generally used for large scale grid electrical power generation. VAWTs are not as common and have only recently been used for large scale electricity generation. Both types of wind turbine are being rigorously tested and improved (Herbert et al., 2007).

Several studies show that the application of the VAWT has more advantages compared to the HAWT. A comparison between the VAWT and the HAWT is presented in Table 1 (Bhutta et al., 2012). The VAWT does not have to be orientated to the wind direction. Also, it does not need a tower hence reducing the capital cost. In fact, the generator is mounted at ground level for easy access. Additionally, recent studies show that VAWTs can be installed much closer to each other compared to HAWTs, so the power density per square meter could be considerably higher than for the configurations used presently (Dabiri, 2011).

For various reasons, there is now a resurgence of interest in VAWTs, in particular Darrieus turbines (Mohamed, 2012). Furthermore, VAWTs exhibit more advantages compared to HAWTs in terms of Malaysia's weather conditions and risks. They harmonise with the circumstances such as low average wind velocity, lightning risk and bird strike risk. The types of VAWT are further analysed and reviewed in the next paragraph

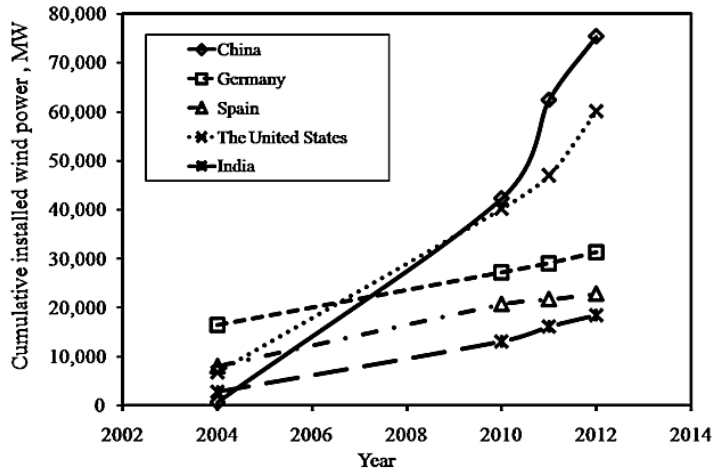

Fig. 2: Total installed wind power for several countries in the world (Leung and Yang, 2012; Herbert et al., 2007).

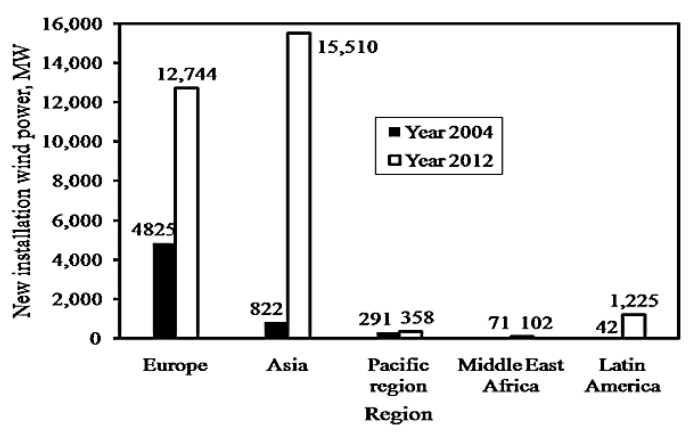

Fig. 3: Trend and new installations of wind power in several regions of the world (Leung and Yang, 2012; Herbert et al., 2007).

Table 1: Comparison between VAWTs and HAWTs (Bhutta et al., 2012)

\begin{tabular}{lc|c|}
\hline & $\begin{array}{c}\text { Vertical axis wind turbine } \\
\text { (VAWT) }\end{array}$ & $\begin{array}{c}\text { Horizontal axis wind turbine } \\
\text { (HAWT) }\end{array}$ \\
\cline { 2 - 3 } $\begin{array}{l}\text { Tower sway } \\
\text { Self-starting }\end{array}$ & Small & Large \\
\hline Overall formation & No & Yes \\
Generator location & No & Yes \\
Height from ground & Simple & Not on ground \\
Blade's operation space & On ground & Large \\
Noise produced & Small & Large \\
\hline Wind direction & Small & Relatively high \\
Obstruction for birds & Less & Dependent \\
Ideal efficiency & Independent & High \\
Wind velocity for start & Less & $50-60 \%$ \\
\hline
\end{tabular}

The study of VAWT configuration has already been conducted and is established. There are several configurations listed, which are as follows: the Darrieus rotor - egg beater shaped (Fig. 4), the Darrieus rotor-variable geometry oval trajectory (VGOT) (Fig. 5), the Darrieus rotor-straight bladed (Fig. 6), the Darrieus-Masgrowe, the twisted three bladed Darrieus rotor, the Crossflex, Savonius rotor (Fig. 7), the Combined Savonius and Darrieus rotor, the two leaf semi rotary, Sistan wind mill and the Zephyr turbine (Bhutta et al., 2012). In terms of the manufacturing process and fabrication costs, the Darrieus rotor-straight blade or giromill showed a reliable configuration. The two blades of the giromill are generally named the H-rotor (Mertens et al., 2003, Howell et al., 2010). Hence, a deep consideration and review will be conducted on the Darrieus rotor-straight blade. In terms of the performance of the VAWT, the central shaft produced a higher impact to the vibration. Besides this, the efficiency of the VAWT is increased by the greater length of the VAWT and the diameter of the turbine blades (Li, 2012).

Previous study on VAWT performance has focused on torque. Several factors influencing VAWT performance were discussed, such as blade health, fluid flow around the blade, and wind turbine design. The studies were conducted using simulation and experimental methods and the VAWT performance was improved.

In design analysis, the design configuration may include a combination of several existing VAWT types (Gavald et al., 1990). A new design of the Darrieus and Savonius combined rotor is proposed and analysed. The starting torque shows an improvement. In addition, a comparison of existing 
standard airfoil shapes was conducted for 20 designs (Mohamed, 2012). From the 20 designs suggested and subjected to computational analysis, the H-rotor Darrieus turbine (involving the S-1046 type of air foil) appears to be very suitable for wind energy generation, particularly in urban areas. Greenblatt et al. (2012) proposed a plasma actuator for controlling the flow separation, hence increasing the power generated by about 38\%. Fixed and variable pitch blades were also studied. The results show that variable pitch blades manage to overcome the starting torque issues associated with VAWTs.

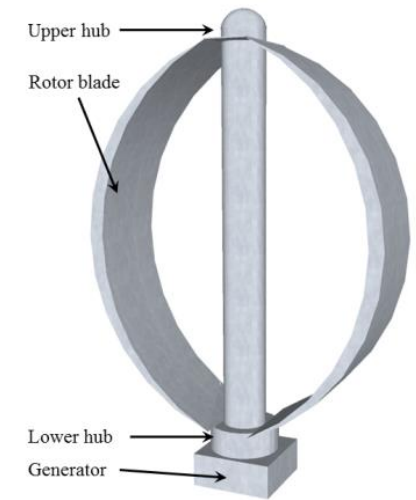

Fig. 4: Darrieus rotor - egg beater shaped (Bhutta et al., 2012)

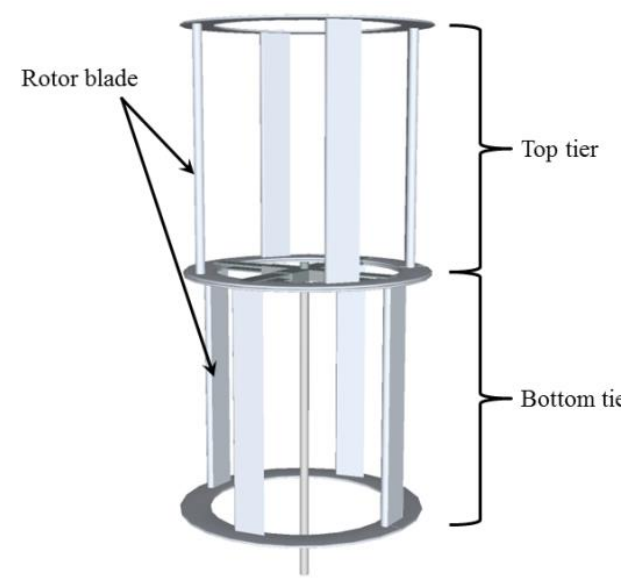

Fig. 5: Darrieus rotor -VGOT (Bhutta et al., 2012)

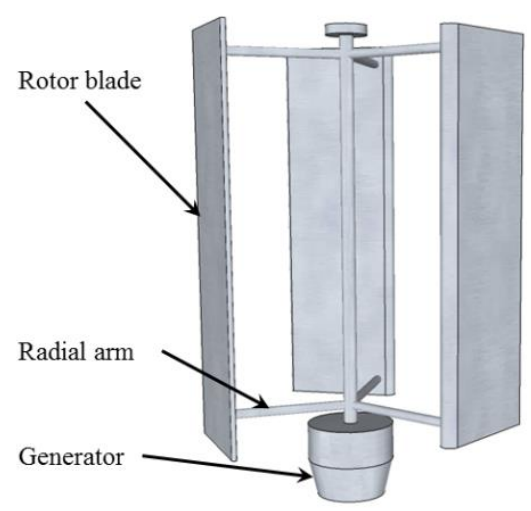

Fig. 6: Darrieus rotor -straight bladed (Bhutta et al., 2012)

Furthermore, the additional accessory may help in improving the amount of power generated. The guide vane at the outer devices of the VAWT system may act as the Bernoulli principle. The reductions in air pressure caused the air to flow into the tunnel at a higher velocity compared to the outer velocity. This improves the rotational speed and the starting behaviour performance.

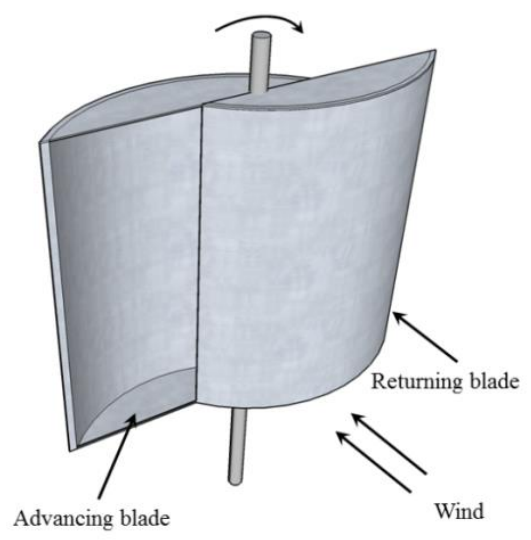

Fig. 7: Savonius rotor (Bhutta et al., 2012)

The experimental output was also supported and enhanced by simulation analysis. The research on vortex simulation, dynamic stall and height-todiameter ratio shows a better understanding and explanation of the aerodynamic problem in the experiment. The selection of codes in computational fluid dynamics analysis is also optimised and improved in the simulation study. Hence, an accurate result could be projected (Tai et al., 2013). An analysis of blade health was conducted as well. It studies the effect of a faulty blade on the torque and power output. It shows that the torque and power could decrease as the number of missing blades increases (Park et al., 2012).

From an economic point of view, one study showed that the improvement in aerodynamic design could benefit by about 6 cent for each $\mathrm{kW} / \mathrm{h}$ generated by the designed VAWT (Saeidi et al., 2013).

Both simulation and experimental methods were conducted to improve the technology of VAWTs, especially for RE fields. The design analysis seems to have reached maturity. Furthermore, the researchers have paid significant attention to the parameters involved, such as aerodynamic performance and fluid flow analysis. However, there are still research opportunities to be pursued in optimising blade design for several factors, such as span length, chord length, manufacturing ability and aerodynamic shape. Further analysis can also be conducted to study those factors which are most influential in VAWT performance. However, the studies on structural integrity need to be explored further; the issues highlighted in structural integrity involve: the structure's critical point, blade vibration utilisation, the effect of the dynamics of wind flow in a very short period, the structural health monitoring system, the natural frequency of the structure and material selection. 


\section{Design of vertical axis wind turbines}

Savonius type turbine is designed with a high drag factor but the frames element of the Savonius type should be designed aerodynamically form to reduce drug force on the wind action for not working elements of turbine. The Darrieus wind turbine follows the aerodynamic principle which compliments the need of Savonius type wind turbine.

The Savonius are one of the simplest self-starting vertical-axis turbines. Aerodynamically, these turbines are drag-type VAWT, so it cannot rotate faster than the wind speed. This means that the tip speed ratio is smaller, making this type of turbines are not suitable for electricity generation. Also, the Savonius turbine consist two or three scoop rotor looks like an "S" configuration in cross section. Referable to the curvature from the shape " $\mathrm{S}$ ", the scoops experience less drag force when going against the wind compared when the scoops moving with the stream of the current of air. This differential drag causes the Savonius turbine to spin. Furthermore, the cavity shape of the blades allows the wind pressure to rotate turbine with low speed and produces a high bending moment along the barb of the turbine due to a large area of the curved components. The efficiency of the turbines is very low compared to other types which are approximately $15 \%$.

Most of the swept area of the Savonius rotor is near the ground, creating the overall energy extraction less effective due to lower wind speed at lower heights. The advantages of this type of VAWTs are the simplicity, the reliability and the very low noise production. It can operate well also at low wind speed because the torque is very high especially in these conditions. Even so the torque are not invariant, thus some improvement like helical shape are used (Fig. 8).

The original design of Darrieus arranged the airfoils in symmetrical ways so that the turbine has zero rigging angles. This example of the correspondence is equally effective no matter which direction the wind is messing up. Furthermore, when the Darrieus rotor is spinning, the control surfaces are going onward through the air in a circular fashion. Proportional to the blade, this oncoming airflow is added vertically to the wind, so that the resultant flow of air creates a varying small positive angle of attack to the vane. As the air foils move around, the angle of attack changes to the opposite sign, only the generated force is still obliquely in the direction of rotation, because the wings are symmetrical and the ringing angle is nothing. As the angle of attack changes, each blade generates its maximum torque at two spots along its wheel (Fig. 10).

The Savonius-Darrieus wind turbine is design by combining the design of Savonius wind turbine and Darrieus wind turbine. By this design, the disadvantages of the two types wind turbine can be covered by each other which is can improve the efficiency and starting torque of the wind turbine.

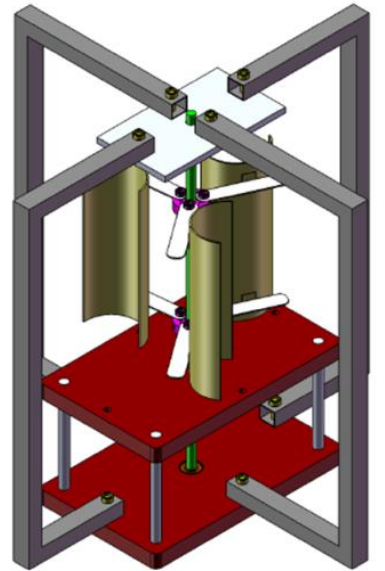

Fig. 8: Design of Savonius wind turbine

The Darrieus wind turbines consist of a bit of straight airfoil blades mounted on the vertical rotating shaft or framework (Fig. 9).

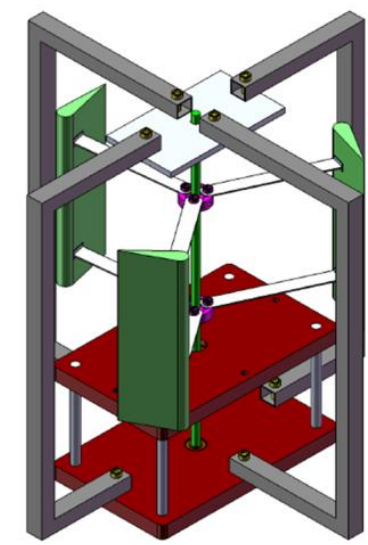

Fig. 9: Design of Darrieus wind turbine

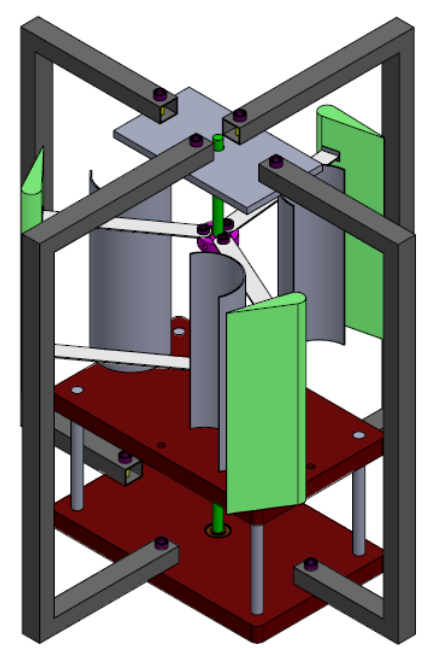

Fig. 10: Design of Savonius-Darrieus wind turbine

\section{Conclusions}

The present Darrieus-Savonius Vertical Axis Wind Turbine design can be suitably placed in the built environment where it can harness more power from wind and, at the same time, would self-start in low wind condition prevalent in such environment. From the preliminary study, there are improvements in the power coefficient and efficiency for the 
Savonius-Darrieus wind turbine compared with the Savonius wind turbine and Darrieus wind turbine only. However, more investigations are on process for confirmation.

\section{References}

Bhutta MMA, Hayat N, Farooq AU, Ali Z, Jamil SR and Hussain Z (2012). Vertical axis wind turbine-A review of various configurations and design techniques. Renewable and Sustainable Energy Reviews, 16(4): 1926-1939.

Carrigan TJ, Dennis BH, Han ZX and Wang BP (2012). Aerodynamic shape optimization of a verticalaxis wind turbine using differential evolution. International Scholarly Research Network, ISRN Renewable Energy, 2012: Article ID 528418. https://doi.org/10.5402/2012/528418

Dabiri JO (2011). Potential order-of-magnitude enhancement of wind farm power density via counter-rotating vertical-axis wind turbine arrays. Journal of Renewable and Sustainable Energy, 3, 043104 (2011). https://doi.org/ $10.1063 / 1.3608170$

Gavalda J, Massons J and Diaz F (1990). Experimental study on a self-adapting Darrieus-Savonius wind machine. Solar and Wind Technology, 7(4): 457-461.

Greenblatt D, Schulman M and Ben-Harav A (2012). Vertical axis wind turbine performance enhancement using plasma actuators. Renewable Energy, 37(1): 345-354.

Hashim H and Ho WS (2011). Renewable energy policies and initiatives for a sustainable energy future in Malaysia. Renewable and Sustainable Energy Reviews, 15(9): 4780-4787.

Herbert GJ, Iniyan S, Sreevalsan E and Rajapandian S (2007). A review of wind energy technologies. Renewable and Sustainable Energy Reviews, 11(6): 1117-1145.

Howell R, Qin N, Edwards J and Durrani N (2010). Wind tunnel and numerical study of a small vertical axis wind turbine. Renewable energy, 35(2): 412-422.
Leung DY and Yang Y (2012). Wind energy development and its environmental impact: a review. Renewable and Sustainable Energy Reviews, 16(1): 1031-1039.

Li L (2012). Vibrations Analysis of Vertical Axis Wind Turbine. M.Sc. Thesis, School of Engineering and Advanced Technology, Massey University, New Zealand.

Marco D and Medaglia M (2010). Vertical axis wind turbines: history, technology and applications. M.Sc. Thesis, School of Business and Engineering (SET), Halmstad University, Sweden.

Mertens S, van Kuik G and van Bussel G (2003). Performance of an H-Darrieus in the skewed flow on a roof. Journal of Solar Energy Engineering, 125(4): 433-440.

Mohamed MH (2012). Performance investigation of H-rotor Darrieus turbine with new airfoil shapes. Energy, 47(1): 522-530.

Park KS, Asim T and Mishra R (2012). Computational fluid dynamics based fault simulations of a vertical axis wind turbines. Journal of Physics: Conference Series, 364(1): 012138. https://doi.org/10.1088/1742-6596/364/1/ 012138

Saeidi D, Sedaghat A, Alamdari P and Alemrajabi AA (2013). Aerodynamic design and economical evaluation of site specific small vertical axis wind turbines. Applied Energy, 101: 765-775.

Savonius SJ (1931). The S-rotor and its applications. Mechanical Engineering, 53(5): 333-338.

Tai FZ, Kang KW, Jang MH, Woo YJ and Lee JH (2013). Study on the analysis method for the vertical-axis wind turbines having Darrieus blades. Renewable Energy, 54: 26-31.

Tjiu W, Marnoto T, Mat S, Ruslan MH and Sopian K (2015). Darrieus vertical axis wind turbine for power generation I: Assessment of Darrieus VAWT configurations. Renewable Energy, 75: 5067. 